\title{
Research on the Possibility of Sorting Application for Separation of Shale and/or Gangue from the Feed of Rudna Concentrator
}

\author{
Andrzej Grotowski ${ }^{1}$, and Kajetan Witecki ${ }^{1}$ \\ ${ }^{1}$ KGHM Cuprum Ltd. Research and Development Center, 53-659 Wrocław, Poland
}

\begin{abstract}
Shale, which occurs in the copper ore deposits belonging to KGHM Polska Miedź S.A., is the reason for a number of difficulties, at the stage of not only processing but also smelting. Gangue, in turn, getting in a feed during mining is a useless load of a concentrator and also contributes to lowering concentrating indexes. Its content in a feed is being evaluated at $15-30 \%$. The multiple attempts to solve those issues by the methods of conventional mineral processing or even selective mining failed. In the range of work, research on the lithological composition and $\mathrm{Cu}$ content in 300 individual particles (selected from Rudna feed) have been carried out. Using those results, the simulation of gangue separation with an application of sorting have been done. The positive results have been received: introduction of a sorting operation causes, theoretically, removing of approximately $20-30 \%$ sorting feed mass as final tailings with $\mathrm{Cu}$ losses not bigger than 5-10\%. It means that the capacity of Rudna concentrator can be increased proportionally. To confirm those results, industrial sorting trials are necessary, when appropriate sorters will become available. Additionally, one should take also into account that the finest classes of feed $(-12.5 \mathrm{~mm})$ could not be concentrated in a sorter. In the range of work, the preliminary tests of the industrial sorter (PRO Secondary Color NIR) for separation of the shale concentrate from Rudna concentrator feed have been carried out. The shale concentrates were received both from $12.5-20 \mathrm{~mm}$ class and $+20 \mathrm{~mm}$ class. The concentrates produced from the coarse classes, for both technological sides had shale content at the level of $48-49 \%$, with recovery of $52.9-60 \%$. In the case of the finer class, shale content in the concentrates for both technological sides amounts to $30.9-35 \%$, at the slightly lower recoveries than for coarse classes. $\mathrm{Cu}$ and Corg behavior in the sorting process were checked also, however, the results turned out to be not very interesting. Because the results of shale concentrate production by sorting have a significant potential for improvement, the further researches in this direction have been recommended, however, making them start off from elaboration of a technology for shale concentrate processing and calculation of a total balance of a concentrating process involving flotation and separation.
\end{abstract}

\section{Introduction}

The presence of shale in $\mathrm{Cu}$ ore, which is processed in KGHM Polska Miedź S.A. concentrators, is the reason of a number of difficulties at the stage of not only processing [1] but also smelting [2-3]. Shale, and actually organic carbon contained in it, causes a higher reagent consumption in flotation process, lowering $\mathrm{Cu}$ content in a concentrate and lowering recovery [3-4]. The high Corg content $(0.51-11.76 \%)$ in shale and - as a consequence in concentrate, makes difficulties even at a smelting stage because of lowering capacity of a smelting furnace. Those unfavorable features of shale made that practically from the moment when the polish copper ore exploitation started in sixties of XX century, the research and tests on removal of shale from the ore or from the produced concentrates began and they are continued up till now. This issue has been explored using different methods only with selective mining, however, the most attention was paid to a flotation method. The research conducted both by research units (IMN, KGHM Cuprum), KGHM Polska Miedź S.A. concentrators, universities (Wrocław Technical University, AGH), and even foreign units, did not allow to elaborate a satisfactory technology. Analyzing properties of shale and flotation process it is unlikely that at this stage of technical development, the problem of shale (Corg) elimination could be solved by a flotation method. Today, the most satisfactory solution, albeit without defects, was found to be the roasting of the concentrate. In this context it is very reasonable to explore the possibility of using new enrichment techniques, such as sorting, for the elimination of slate.

Another issue connected to mining exploitation of deposits, including the polish $\mathrm{Cu}$ deposits, is contamination of feed by gangue, and related to this, its dilution. Dilution of feed is unavoidable and is a consequence of used mining methods and machines. For those reasons, it never could not be eliminated completely and the only reasonable solution is to keep it in acceptable limits [5]. According to the conservative evaluation,

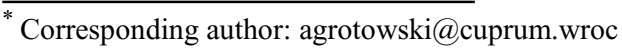


approximately $15-30 \%$ of the mining output in KGHM Polska Miedź S.A. constitutes the most probably gangue with $\mathrm{Cu}$ content lower than $0.05-0.10 \%$. Its elimination from a concentrator feed would improve the throughput of the $\mathrm{Cu}$ concentrators and the current technological indexes [6-7].

A sorting process creates a chance to solve both above mentioned issues (shale and gangue presence in a feed). This is even more justified as the turbulent development of sorting techniques has led to the construction of a number of new sensors and sorting machines, resuming research in this field, and the introduction of many sorters into industrial practice [8].

The results of the research on the possibility of sorting application both for shale concentrate production and for gangue removal from the $\mathrm{Cu}$ ore processed in Rudna concentrator have been presented in this paper.

\section{Sorting techniques}

Sorting is separation of a material into two or more products with different required properties. Due to the sensor abilities to detect the properties of individual grains and technical possibilities of their effective separation, sorting is usually limited to particles with size from 10-15 $\mathrm{mm}$ to $250-300 \mathrm{~mm}$ [9-10]. Hence, sorting process can only be used for sufficiently coarse feed.

Although, manual sorting is used since the dawn of action, the first mechanical sorter was constructed only in XIX century [11]. This was made possible by the development of suitable sensors to enable efficient separation of particles. The first commercial sorter, which was based on the detection of optical properties, appeared only in 1931, in the food industry [12]. Since then, mechanical sorting has begun to supplant manual sorting, and in the late 1960 s many branches of industry abandoned manual sorting [13-14].

However, even today in some situations manual sorting is irreplaceable, e.g. due to the specific characteristics of the raw materials (food industry, waste recycling) [15] economic conditions, small scale of production, special limitations, etc.

Regardless of sorting is done manually or mechanically, its effectiveness requires the following conditions $[11-12,16]: 1)$ proper preparation and feeding of a raw material for a separation process; 2) effective detection of a required parameter; 3 ) faultless and fast identification of particles with the desired properties and; 4) fast physical separation of a raw material for the required products.

In mining, sorting machines are used primarily in diamond mining, which since the 1960s has used optical sorters for this purpose. They are currently being displaced by X-ray luminescence (XRL) sensors and near-infrared (NIR) ones [8, 17-19]. However, the most promising solution, despite low throughput, seems to be the use of sensors that work on the principle of XRT [20]. The use of this technology allowed the separation of large diamonds with low luminescence, or closed in the gangue, and especially enabled the recovery of much larger diamonds than it was possible previously.
Sorting machines were introduced for the first time in the food industry which is still the source of new sorting technologies. More and more widespread use for food distribution in the food industry is the near infrared (NIR) technology [21-23]. Using this technology allows to capture the imperfection of the material or to obtain statistical correlations between a spectra obtained and a content of selected substances [23]. This solution is usually used in conjunction with optical sensors, allowing for easy and accurate separation of main components of homogeneous materials (e.g. copper ores). Currently, HSI (Hyperspectral Imaging) technology is at the stage of development and research. In general, HIS uses spectra of each pixel what makes it possible to create 3D models, showing the distribution of the components in individual particles [21, 24-25].

The pursuit of recycling (circular economy) requires the use of solutions that allow for the separation of waste products into the separate products with the required properties. Sorting machines have been successfully used by the Sense2Sort consortium, which combines Austin Al and Toratecnica to separate scrap aluminum from mixed metal scrap [26]. The proposed solution uses XRF and LIBD (Laser Induced Breakdown Spectroscopy) technology. The whole process runs automatically and delivers a product of up to $98 \%$ purity in ready-to-recycle form. Secondary aluminum recovery saves up to $95 \%$ energy, compared to the original production of this metal from bauxite [26]. Much more difficult is a separation of municipal wastes, which in order to be reused must be separated, first and foremost, into organic and inorganic components [27]. The authors used various methods for this purpose, resulting in the separation of leachates, plastics, metals, paper and organic fraction. The sorting methods used included both manual, magnetic, pneumatic and hydraulic separation. The necessity of using so many separation methods in a single technological chain was due to the complexity of the waste delivered. In the case of copper ores, the simplest way to eliminate the gangue would be to use a $\mathrm{Cu}$ content sensor, based on the X-ray fluorescence principle. However, according to the opinion of one of the major producers of sorters - Commodas Ultrasort [10], it is currently not possible to construct a sorting machine operating on this principle which could provide sufficiently efficient sorting and to obtain a low$\mathrm{Cu}$ product. Therefore, the possibility of eradicating shale from Rudna ore was determined by examining the $\mathrm{Cu}$ content in selected grains and performing on this basis a sorting simulation [28] and the possibility of producing shale concentrate was verified by the use of an industrial sorter.

\section{Materials and methods}

The copper ore samples for gangue removal were collected in Rudna concentrator from belt conveyors transporting ore from the fine ore bins to the conveyors transporting ore to mills (I-st stage mills). The subject of the tests were both types of ore: the ore from A side (with increased content of sandstone) and the ore from B side (with elevated carbonates content). The collected 
samples, weighing about $250 \mathrm{~kg}$, were individually averaged and reduced by the quartering method, finally receiving 4 samples: 2 samples weighting about $50-60 \mathrm{~kg}$ and 2 samples with approximately $5 \mathrm{~kg}$ each, representing A and B technological sides. Smaller samples, weighing about $5 \mathrm{~kg}$ each, were subjected to sieve analysis. The results are shown in Figure 1.

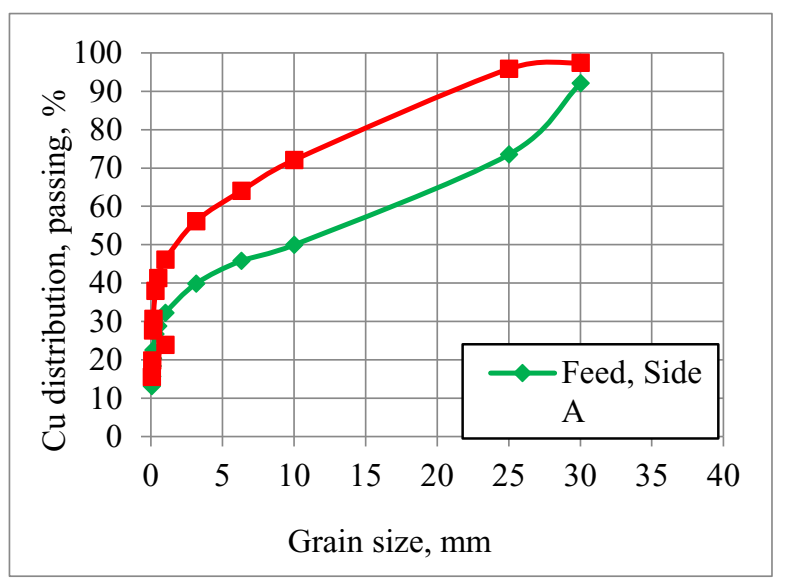

Fig. 1. The particle size distribution of the feeds for the individual technological sides, Rudna concentrator.

In the obtained particle classes, the $\mathrm{Cu}$ content was determined and $\mathrm{Cu}$ distribution was calculated on this basis. The results are displayed in Figure 2.

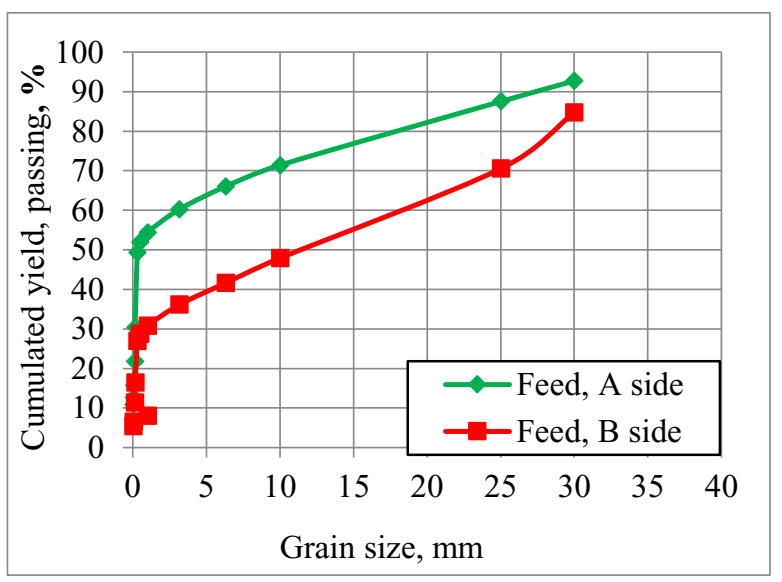

Fig. 2. Distribution of $\mathrm{Cu}$ in the particle classes of the feeds for the individual technological sides of Rudna concentrator.

Subsequently, the bigger samples were sieved through a $12.5 \mathrm{~mm}$ sieve to remove non-sortable material. Then each sample was manually sorted into shales, carbonates (limestone) and sandstones. In total, 300 particles representing all lithological ore components were extracted for A and B sides. Prior to the manual sorting, the particles were washed with water to clean the surface from dust in order to facilitate visual identification. After completion of manual sorting, the individual particles were crushed and sent to CBJ (Quality Research Centre) in Lubin to determine the $\mathrm{Cu}$ content by ICP-MS method.

The copper ore samples (from A and B sides) for shale separation in the industrial sorter were collected in Rudna concentrator too. The mass of each sample taken was approximately $1.5 \mathrm{Mg}$. Then the samples were sent to Commodas Ultrasort Test Center (now Outotec) in Wedel, Germany, where material was screened by 12.5 $\mathrm{mm}$ screen. The $-12.5 \mathrm{~mm}$ class was saved for subsequent flotation test and $+12.5 \mathrm{~mm}$ class was screened into 12.5 $20 \mathrm{~mm}$ and $+20 \mathrm{~mm}$ classes. Finished classes were rinsed with water to clean the surface in order to improve detection in the sorting process. PRO Secondary Color NIR sorter was used for all sorting tests. The sorter calibration was performed using the "rock-by-rock" results for 123 individual particles, selected from the ore samples and representing all lithological types. The lithological type of the individual particles was determined as well as $\mathrm{Cu}$ and other components content by the XRF method. Then, using such characterized particles, the possibility of using different sensors, based on such phenomena as NIR, color photometry, XRT and electromagnetism, to sort ore was investigated. The best results of detection for shale were obtained with NIR and photometric sensors and they have been selected for the sorting tests described further.

\section{Results and discussion}

\subsection{Research on the elimination of gangue}

Based on the analysis of $\mathrm{Cu}$ content in the individual particles of carbonates, sandstones and shales, which have been selected from the both sides of Rudna concentrator, the average $\mathrm{Cu}$ content in a given lithological type, the yield of a given lithological type, and the distribution of $\mathrm{Cu}$ in them were determined.

Table 1. Average $\mathrm{Cu}$ content in a given lithological type, lithological type yield and $\mathrm{Cu}$ distribution.

\begin{tabular}{|c|c|c|c|c|c|c|}
\hline \multirow{2}{*}{$\begin{array}{c}\text { Lithologic } \\
\text { al type }\end{array}$} & \multicolumn{2}{|c|}{ Cu cont., \% } & \multicolumn{2}{c|}{ Yield, \% } & \multicolumn{2}{c|}{$\begin{array}{c}\text { Cu } \\
\text { distribution, \% }\end{array}$} \\
\cline { 2 - 7 } & \multicolumn{2}{|c|}{ Side } & \multicolumn{2}{|c|}{ Side } & \multicolumn{2}{c|}{ Side } \\
\cline { 2 - 7 } & $\mathbf{A}$ & B & A & B & A & B \\
\hline Shales & 3.57 & 1.49 & 10.9 & 10.1 & 25.3 & 14.2 \\
\hline Sandstones & 1.46 & 1.14 & 49.1 & 46.7 & 46.6 & 50.3 \\
\hline Carbonates & 1.08 & 0.87 & 40.0 & 43.2 & 28.1 & 35.5 \\
\hline
\end{tabular}

The shale content in the ore from both technological sides (A and B) fluctuates around the limit of about 10\%, with the $\mathrm{Cu}$ content in it being significantly higher on side A. The largest share, on both sides, is observed for sandstones, but the share of carbonates is only slightly smaller. One can see minimal variation in the lithological composition between the individual sides.

Table 2 summarizes the basic statistics concerning the copper content in the individual grains of particular lithological types such as mean, minimum, maximum, standard deviation (SD) and relative standard deviation (RSD).

Shales on both technological sides are characterized by high variability, which can certainly be affected by the difficulty of identifying this lithological type, when compared to carbonates. However, the greatest variability was found for carbonates on B side. From the point of view of the possibilities for elimination of gangue, the 
most important feature of the presented results is the presence of particles with relatively low $\mathrm{Cu}$ content $(0.04$ to $0.11 \%$ ).

Table 2. The basic statistics of $\mathrm{Cu}$ content in the particular lithological types of the feeds for the both technological sides, Rudna concentrator.

\begin{tabular}{|c|c|c|c|c|r|r|}
\hline \multirow{2}{*}{ Statistics } & \multicolumn{2}{|c|}{ Sandstone } & \multicolumn{2}{c|}{ Carbonate } & \multicolumn{2}{c|}{ Shales } \\
\cline { 2 - 7 } & \multicolumn{2}{|c|}{ Side } & \multicolumn{2}{c|}{ Side } & \multicolumn{2}{c|}{ Side } \\
\cline { 2 - 7 } & A & B & A & \multicolumn{1}{c|}{ B } & \multicolumn{1}{c|}{ A } & \multicolumn{1}{c|}{ B } \\
\hline Average & 1.46 & 1.14 & 1.14 & 1.08 & 3.57 & 1.49 \\
\hline Min & 0.04 & 0.06 & 0.06 & 0.08 & 0.10 & 0.04 \\
\hline Max & 5.52 & 3.70 & 3.70 & 5.12 & 19.36 & 12.56 \\
\hline SD & 1.19 & 0.80 & 0.80 & 2.02 & 4.70 & 2.44 \\
\hline RSD, \% & 81.6 & 69.9 & 69.9 & 186.5 & 131.6 & 164.41 \\
\hline
\end{tabular}

The simulation of the sorting results was carried out using all the results of $\mathrm{Cu}$ content in individual particles, separately for A and B sides. For all cases, such limit concentrating indexes were set, that the total $\mathrm{Cu}$ losses in tailings were not higher as $5-10 \%$ (for the total $\mathrm{Cu}$ recovery in concentrate not lower than 90-95\%). Under such assumptions, the total output of the gangue, read from the corresponding concentration curves for tailings, varies between $20-30 \%$. Such mass of the ore can safely be discarded during a separation processes, without significantly impairing the flotation performance. The results of the simulated enrichment (sorting) curves for A and B sides are shown in Figures 3 and 4, respectively.

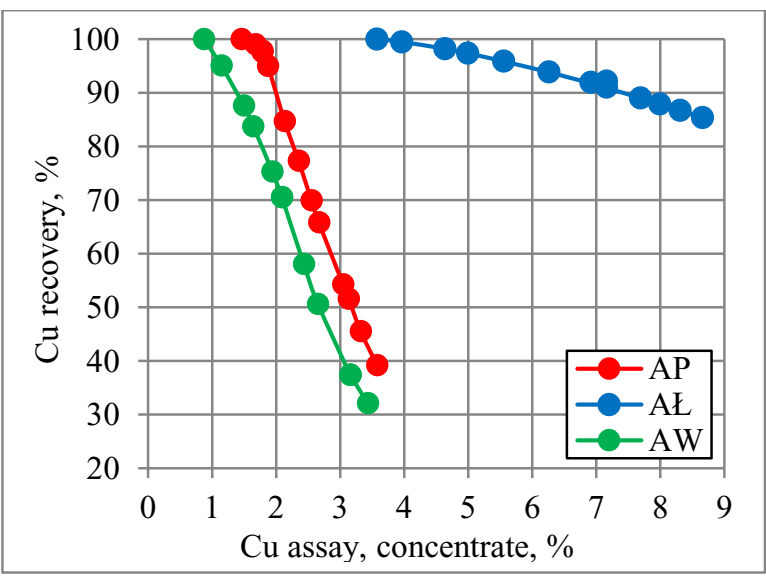

Fig. 3. Sorting simulation of Rudna concentrator feed - A side, class $+12.5 \mathrm{~mm}-\mathrm{Cu}$ recovery for the individual lithological components vs $\mathrm{Cu}$ assay in concentrate (AP - sandstones, A side; AŁ - shale, A side; AW - carbonates, A side).

The presented results show that the sortability of carbonates (W) and sandstones (P) from both technological sides A and B is very similar, whereas the sortability of shale $(\mathrm{E})$ - on both sides is quite far from the other components. However, if you judge it by the practical concentration index, shale turn out to be the best sortable of all three lithological components.

The obtained simulation results should be treated as the preliminary ones, because in the case of sorting in an actual sorter, the concentration indexes for a number of reasons (for example less efficient particle spreading, contamination of particle surface, imperfection of detection algorithm, and overall sorter efficiency compared to manual sorting) will be worse.

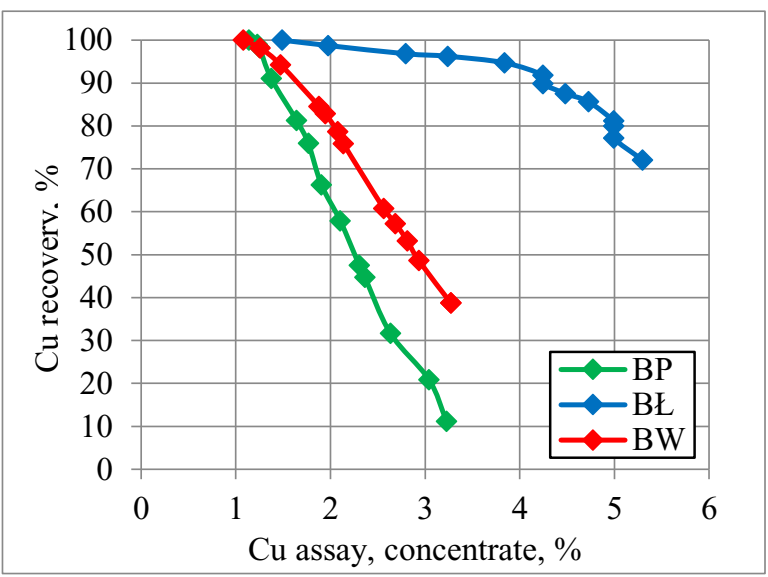

Fig. 4. Sorting simulation of Rudna concentrator feed - B side, class $+12.5 \mathrm{~mm}-\mathrm{Cu}$ recovery for the individual lithological components vs $\mathrm{Cu}$ assay in concentrate ( $\mathrm{BP}$ - sandstones, $\mathrm{B}$ side; $\mathrm{B} \ell$ - shale, B side, BW - carbonates, B side).

\subsection{Research on the production of shale concentrate}

Four products obtained from the Rudna concentrator, i.e. classes $12.5-20 \mathrm{~mm}$ from $\mathrm{A}$ and $\mathrm{B}$ sides $\mathrm{A}$, classes $+20 \mathrm{~mm}$ also from $\mathrm{A}$ and $\mathrm{B}$ sides, were concentrated in the industrial sorter. The main purpose of the tests was to obtain a rich shale concentrate. The lithological composition of each product was determined as well as $\mathrm{Cu}$ and Corg content. The shale content in the sorting products was determined on the basis of macroscopic features, while the $\mathrm{Cu}$ and Corg content was determined in ICP-MS method by CBJ (Quality Researcg Centre) in Lubin. The sorting results are displayed in Table 3.

Generally, the richest concentrates, with a shale content close to $50 \%$, were obtained for a grain class $+20 \mathrm{~mm}$. Also, they are characterized by the quite high concentrating ratios, amounting to, depending on the technological side, from 4.2 to 4.6. The yield of shale concentrate is not too high, but the general purpose of the tests was to obtain a possibly rich concentrate. For finer classes $(12.5-20 \mathrm{~mm})$ the results are worse - in every respect - than for the coarser classes, what is in line with expectations.

The obtained concentrates did not show significantly increased copper content or concentrating ratio. The highest value of a concentration ratio, amounting to 2.1 was obtained under Test I, then for Test III and IV, it was 1.6 and 1.4, respectively. The least enriched in copper proved to be the concentrate from test II, where a concentration ratio amounted to 1.2 only. The highest value of a concentration ration, amounting to 2.1 , was obtained under Test I, then for Test III and IV, it was 1.6 and 1.4, respectively. The least enriched in copper proved to be the concentrate from Test II, where a concentration ratio was 1.2 .

The organic carbon content in the concentration products was also determined, to find how much shale 
concentration is correlated with this components. The separation results are shown in Table 4.

The results show that although the correlation between shale and Corg content exists, it is not sharp. In the concentrates obtained in tests I and II (coarse class, A and $\mathrm{B}$ sides), the shale content is close to $50 \%$ (See Tab. 3) but the Corg content in test I (coarse class, side A and B) amount to as low as $2.87 \%$ and $1.49 \%$. On the phenomenon of low correlation of shale and Corg contents, especially in the industrial flotation circuits, attention has already been paid in the previous works [29-30].

Nevertheless, the analysis of the content of organic carbon in sorting products shows a markedly increased content of it in the shale concentrate. The highest concentration ratio of Corg, equal to 4.5, was achieved with Test I, in the successive tests the ratios amounted to 3.5 - Test II and III, and only 2.5 - Test IV.

Although the purpose of the tests in the industrial sorting machine was to determine the possibility of shale separating from copper ore, the $\mathrm{Cu}$ content was also determined in the products obtained. The results are listed in the same table. As expected, copper - both in terms of $\mathrm{Cu}$ content in concentrate, concentration ratio and yield is concentrated significantly worse off than Corg. This is due to the presence forms of these two components in the $\mathrm{Cu}$ ore studied and the concentration method used.

Table 3. Sorting results of shale from Rudna $\mathrm{Cu}$ ore, A and B sides, particle class $12.5-20 \mathrm{~mm}$ and $+20 \mathrm{~mm}$.

\begin{tabular}{|c|c|c|c|c|c|c|c|c|}
\hline \multirow{2}{*}{$\begin{array}{c}\text { Test } \\
\text { no }\end{array}$} & \multirow[t]{2}{*}{ Side } & \multirow{2}{*}{$\begin{array}{c}\text { Particle class, } \\
\text { mm }\end{array}$} & \multirow[t]{2}{*}{ Product } & \multicolumn{2}{|c|}{ Yield } & \multirow{2}{*}{$\begin{array}{c}\text { Shale } \\
\text { content, \% }\end{array}$} & \multirow{2}{*}{$\begin{array}{c}\text { Shale } \\
\text { recovery, } \\
\%\end{array}$} & \multirow[t]{2}{*}{ Concentr.ratic } \\
\hline & & & & kg & $\%$ & & & \\
\hline \multirow{3}{*}{$\mathbf{I}$} & \multirow{3}{*}{ A } & \multirow{3}{*}{+20} & Concentrate & 16.1 & 11.57 & 49.0 & 52.9 & 4.6 \\
\hline & & & Tailing & 123 & 88.43 & 5.7 & 47.1 & - \\
\hline & & & Feed & 139.1 & 100.00 & 10.7 & 100.0 & 1.0 \\
\hline \multirow{3}{*}{ II } & \multirow{3}{*}{ B } & \multirow{3}{*}{+20} & Concentrate & 31.5 & 14.35 & 48.7 & 60.9 & 4.2 \\
\hline & & & Tailing & 188.0 & 85.65 & 5.2 & 39.1 & - \\
\hline & & & Feed & 219.5 & 100.00 & 11.5 & 100.0 & 1.0 \\
\hline \multirow{3}{*}{ III } & \multirow{3}{*}{ A } & \multirow{3}{*}{$12.5-20$} & Concentrate & 17.0 & 16.11 & 35.0 & 45.1 & 2.8 \\
\hline & & & Tailing & 88.5 & 83.89 & 8.2 & 54.9 & - \\
\hline & & & Feed & 105.5 & 100.00 & 12.5 & 100.0 & 1.0 \\
\hline \multirow{3}{*}{ IV } & \multirow{3}{*}{ B } & \multirow{3}{*}{$12.5-20$} & Concentrate & 37.1 & 22.96 & 30.9 & 56.7 & 2.2 \\
\hline & & & Tailing & 124.5 & 77.04 & 8.9 & 54.9 & - \\
\hline & & & Feed & 161.6 & 100.00 & 14.0 & 111.6 & 1.0 \\
\hline
\end{tabular}

Table 4. Sorting results of Corg and $\mathrm{Cu}$ from Rudna ore, A and B side, 12.5-20 mm and $+20 \mathrm{~mm}$.

\begin{tabular}{|c|c|c|c|c|c|c|c|c|c|}
\hline $\begin{array}{l}\text { Test } \\
\text { no }\end{array}$ & Side & $\begin{array}{c}\text { Grain } \\
\text { class, } \mathbf{m m}\end{array}$ & Produkt & $\begin{array}{c}\text { Corg } \\
\text { content, \% }\end{array}$ & $\begin{array}{c}\text { Corg } \\
\text { recovery, } \\
\%\end{array}$ & $\begin{array}{l}\text { Corg conc. } \\
\text { ratio }\end{array}$ & $\begin{array}{c}\text { Cu cont., } \\
\%\end{array}$ & $\begin{array}{c}\text { Cu reco- } \\
\text { very, } \\
\%\end{array}$ & $\begin{array}{l}\text { Cu conc. } \\
\text { ratio }\end{array}$ \\
\hline \multirow{3}{*}{ I } & \multirow{3}{*}{ A } & \multirow{3}{*}{+20} & Concentrate & 2.87 & 51.77 & 4.5 & 3.13 & 24.69 & $2 ., 1$ \\
\hline & & & Tailing & 0.35 & 48.23 & - & 1.25 & 75.31 & - \\
\hline & & & Feed & 0.64 & 100.00 & 1.0 & 1.47 & 100.00 & 1.0 \\
\hline \multirow{3}{*}{ II } & \multirow{3}{*}{ B } & \multirow{3}{*}{+20} & Concentrate & 1.49 & 50.00 & 3.5 & 1.82 & 1770 & 1.2 \\
\hline & & & Tailing & 0.25 & 5000 & - & 1.42 & 82.30 & - \\
\hline & & & Feed & 0.43 & 100.00 & 0.3 & 1.48 & 100.00 & 1.0 \\
\hline \multirow{3}{*}{ III } & \multirow{3}{*}{ A } & \multirow{3}{*}{$12.5-20$} & Concentrate & 2.57 & 57.20 & 3.5 & 2.86 & 25.13 & 1.6 \\
\hline & & & Tailing & 0,37 & 42.80 & - & 1.64 & 74.87 & - \\
\hline & & & Feed & 0.73 & 100.00 & 1.0 & 1.84 & 100.00 & 1.0 \\
\hline \multirow{3}{*}{ IV } & \multirow{3}{*}{ B } & \multirow{3}{*}{$12.5-20$} & Concentrate & 1.56 & 57.77 & 2.5 & 1.94 & 32.89 & 1.4 \\
\hline & & & Tailing & 0.34 & 42.23 & - & 1.18 & 67.11 & - \\
\hline & & & Feed & 0.62 & 100.00 & 1.0 & 1.35 & 100.00 & 1.0 \\
\hline
\end{tabular}

\section{Conclusions}

1. The conducted tests and simulations of $\mathrm{Cu}$ ore sorting in order to extract the gangue (product with significantly reduced $\mathrm{Cu}$ content in comparison to $\mathrm{Cu}$ ore) have shown that this is theoretically possible. Using the results of the $\mathrm{Cu}$ content in individual ore particles, $\mathrm{Cu}$ losses in tailings were determined to be no more than $5-10 \%$. It means that about $20-30 \%$ of ore can be removed as final tailing on the stage of sorting. As a result, the mass of feed to flotation will fall to $70-80 \%$ primary ore mass. It can be expected that the capacity of the flotation concentrator will increase by $20-30 \%$, also. Determining the actual effect will require performing concentration tests in an actual sorting machine because its concentration efficiency will be lower than the simulation results. Also note that the smallest grades $(-12.5 \mathrm{~mm})$ cannot be enriched in the sorter. However, further tests will only be 
justified when the possibilities for constructing sorting machines based on the $\mathrm{Cu}$ content criterion appear.

2. Preliminary tests using an industrial sorter to produce shale concentrate from the flotation feed have also shown that this is possible. It has been found that from the fed of Rudna concentrator, class $+20 \mathrm{~mm}$, it is possible to obtain the shale concentrate with a shale content of $48-49 \%$ and a concentrate yield of $52.9-60 \%$. For the finer class $(12.5-20 \mathrm{~mm})$ - for both technological lines - shale content in the concentrate amounts to $30.9-35 \%$. Due to the existing potential for results improvement, further research in this direction could be justified, however, any possible work in this direction should be preceded by elaboration of a method of shale concentrate processing and execution of the overall balance of the ore concentrating process (sorting + flotation).

3. The sorting tests carried out have yielded very interesting results in terms of the applicability of this solution to the separation of Rudna concentrator feed into products with different lithological characteristics and different copper content. For the obtained sorting products it is planned to examine the content of the accompanying metals and determine their flotability. It is also necessary to check the flotability of the finest class $(-12.5 \mathrm{~mm})$, to develop a complete balance of the enrichment process.

This paper is part of the collaborative research project Ecometals co-funded by German Federal Ministry of Education and Research (BMBF under the Grant ID 033RF001), French National Research Agency (ANR-13-RMNP-0006) and KGHM Polska Miedź S.A. (KGHM-BZ-U-0319-2014). The authors also would like to thank UVR-FIA GmBh, Freiberg, Germany for screening the ore to the big-scale tests and Tomra Sorting $\mathrm{GmbH}$ Wedel, Germany for the execution of the big-scale sorting tests.

\section{References}

1. A. Grotowski, K. Sztaba, A. Wieniewski, Cuprum Ore Min. Sci. Tech. Mag. 2(47), 105-124 (2008)

2. J. Czernecki, S. Sobierajski, Z. Śmieszek, EMC `91, (Elsevier Applied Science, London - New York, 1991)

3. B. Skorupska, A. Wieniewski, N. Kubacz, Min. Geol., 6(2), (2011)

4. Collective development, Monografia KGHM Polska Miedź S.A. (KGHM Polska Miedź S.A, Lubin, 2007).

5. E.A. Wright, Erzmetall, 36(1), 23-29 (1983)

6. T.R. Hughes, G. Cormack, , First International Future Mining Conference (Sydney, 1-8, 2008)

7. P. Whiteway, www.canadianminingreview.com/ 2011/03/nickel-exploration.html (2011)

6. S. Walker, Eng. Min. J. 215(4), 46 (2014)

7. B.A. Wills,: Will's Mineral Processing Technology (Butterworth-Heinemann, Queensland, 2006)
8. A. Grotowski, K. Witecki, Personal data: Application of sorters in kimberlite ores enrichment (Wedel, 2016).

9. J.D. Salter, N.P.G. Wyatt, XVII Intern. Miner. Proc. Congr., (Dresden, 5, 183-193, 1991a)

10. J.D. Salter, N.P.G. Wyatt, Mineral Engineering, 7(11),779-796. (1991b)

11. D.L. Carson, A.T. Moir, Proc. VII Comm. Mitt. Metall. Inst. Congr.. (Johannesburg. S.Afr. Inst. Min. Metall., 1961)

12. J.S. Freer, R.C. Bohme, Proc. Mintek 50, Intern. Conf. recent Advances in Miner. Sci. Technol., (Johannesburg, 36-37, 1984)

13 A. Procner, Technologia gastronomiczna $z$ towaroznawstwem (Wydawnictwo Szkolne i Pedagogiczne, Warszawa, 1988)

14. H.R. Manouchehri, Proc. of Conference of Mineral Processing (Luleå, 1-17 (2003)

15. Anon., Min. Eng. J., 17 (1971)

16. M.G. Rylatt, G.M. Popplewell, Miner. Eng., 51, 3743 (1999)

17. T. Mahlangu, N. Meomise, M.M. Ramakokovhu, P.A. Olubambi, M.B. Shongwe, J. South. Afr. Inst. Min. Metall., 116, 343-347 (2016)

18. L.M. van Niekerk, A Olivier, J. Armstrong, N.A. Sikwa, J. South. Afr. Inst. Min. Metall., 116, 709-714 (2016)

19. R. Moscetti, W. Saeys, J.C. Keresztes, M. Goodarzi, M. Cecchini, M. Danilo, R. Massantini, Food Bioprocess Technol, 8, 1593-1604 (2015)

20. X. Wu, B. Wu, J. Sun, M. Li, H. Du, Int. J. Food Prop., 19, 1016-1028 (2016).

21. J.A. Cayuela, J.F. Garcia, J. Food Eng., 202, 79-88 (2017)

22. M.F. Carlsohn, .J Real-Time Image Proc., 1, 25-32 (2006)

23. G. Elmasry, M. Kamruzzaman, D.-W. Sun, P. Allen, Crit. Rev. Food. Sci. Nutr., 52(11), 999-1023 (2012)

24. E.-M. Gerosch, E. van Looy, Aluminium Int. Today, 25-27 (2016)

25. H. Wang, J. Xu, H. Yu, X. Liu, W. Yin, Y. Liu, Z. Liu b, T. Zhang, Renew. Susta. Energy Rev., 52, 1881-1889 (2015)

26. A. Grotowski, A. Szubert, Cuprum Ore Min. Sci. Tech. Mag., 2 (75),123-136 (2016)

27. A. Grotowski, Konferencja „Perspektywy zastosowania technologii bioługowania do przerobu rud miedzi zawierających łupki - BIOPROCOP '06” (Lubin, 7-27, 2006)

28. P. Kijewski, R. Leszczyński, Zeszyty Naukowe Instytutu Gospodarki Surowcami Mineralnymi i Energi Polskiej Akademii Nauk, 79 (2010) 